\title{
Research Paper: Predictors of Healthcare Expenditure: Aging, Disability or Development?
}

\author{
Behzad Karami Matin $^{1}$, Ali Kazemi Karyani ${ }^{1} \odot{ }^{*}$ Shahin Soltani ${ }^{1} \odot$, Moslem Soofi $^{1}$, , Satar Rezaei ${ }^{1}$
}

1. Research Center for Environmental Determinants of Health, Health Institute, Kermanshah University of Medical Sciences, Kermanshah, Iran.

\begin{tabular}{c|c}
$\begin{array}{c}\text { Use your device to scan } \\
\text { and read the article online }\end{array}$ \\
Disability or Development? (Persian)]. Archives of Rehabilitation. 2020; 20(4):310-321. http://dx.doi.org/10.32598/rj.20.4.310 \\
d.t. http://dx.doi.org/10.32598/rj.20.4.310
\end{tabular}

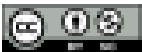

Received: 14 Jun 2019 Accepted: 25 Nov 2019 Available Online: 01 Jan 2020
Keywords:

Aging, Disability Economic development, Global disease burden, Healthcare expenditure, Developing countries

\section{ABSTRACT}

Objective Studies show that almost every country across the world will experience a remarkable increase in their healthcare costs and ageing population by 2030. Also, people with disabilities are more likely to impose considerable healthcare costs on families and governments than their counterparts. On the other hand, socioeconomic status of countries can be an important factor to predict healthcare costs. In this study, we aimed to evaluate the relationship between disability rate, ageing rate and development rate of countries with their current health expenditure.

Materials \& Methods This is a descriptive correlational study conducted based on secondary analysis of existing data of 202 countries under six different regions of African Region (AFRO), Eastern Mediterranean Region (EMRO), South-East Asia Region (SEARO), Western Pacific Region (WPRO), European Region (EURO), and Region of the Americas (PAHO) in 2016. The linear regression analysis was applied to investigate the association between the explanatory variables of age, Years Lost due to Disability (YLD) per 100000 general population, Human Development Index (HDI), Gross Domestic Product (GDP) growth, and unemployment rate with Current Health Expenditure (CHE) per capita as the outcome variable. The costs were expressed based on Power Purchasing Parties (PPP) in USD. One-way ANOVA was applied to compare the means of YLD and CHE per capita between three levels of HDI.

Results The highest mean YLD (13272.76 \pm 1577.22 per 100000 general population) and mean $\mathrm{CHE}$ (2698.39 \pm 1915.01 USD) was belonged to EURO region, while AFRO region showed the lowest mean YLD (10005.65 \pm 847.03 per 100000 general population) and mean CHE (281.11 1335.84 USD). In Iran, the mean YLD and CHE was lower than that of EURO region but higher than that of other five regions. EURO, PAHO, and WPRO had the highest rate of ageing compared to other regions. For Iran, the rate of ageing population was higher than AFRO and EMRO. In the regression model, population aged 15 to 49 ( $Y L D=0.167)$, aged $>65$ years ( $Y L D=0.651$ ), aged $\geq 70$ years ( $Y L D=0.359)$ and $H D I(0.391)$ had a positive association with the CHE per capita. In contrast, the population aged $\leq 5$ years (YLD=-0.585), aged 15-64 years ( $Y L D=-0.274)$, and aged $50-69$ years $(Y L D=-0.938)$ and the unemployment rate $(-0.138)$ showed a negative association with the $\mathrm{CHE}$ per capita. Moreover, ANOVA results revealed that the rate of ageing population $(P<0.001)$, YLD $(P<0.001)$ and CHE per capita $(P<0.001)$ were significantly higher in countries with higher HDI than in countries with lower HDI.

Conclusion In the study period, YLD can predict healthcare expenditure of countries better compared to $\mathrm{HDI}$ and ageing population. Therefore, it is suggested that cost control interventions in ageing period should be implemented through programs aimed at preventing chronic diseases.

\section{* Corresponding Author:}

Shahin Soltani, PhD.

Address: Research Center for Environmental Determinants of Health, Health Institute, Kermanshah University of Medical Sciences, Kermanshah, Iran Tel: +98 (918) 3550106

E-Mail: sh-soltani@alumnus.tums.ac.ir 


\title{
بيشبينى كنندهاى هزينهاي سلامت: سالمندى؛ ناتوانى يا توسعهيافتكى؟
}

\author{
بهزاد كرمى متين' ، على كاظمى كريانى' ، "شاهين سلطانى' •، مسلم صوفى' ه، ستار رضايى' \\ 1. مركز تحقيقات عوامل محيطى موثر بر سلامت، يرؤشكده سلامت، دانشكاه علوم يزشكى كرمانشاه، كرمانشاه، ايران.
}

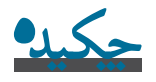

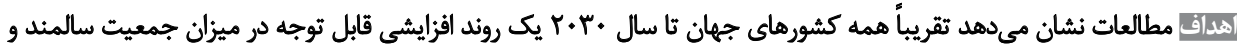

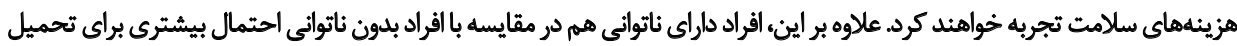

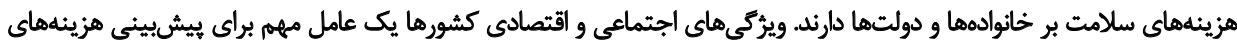

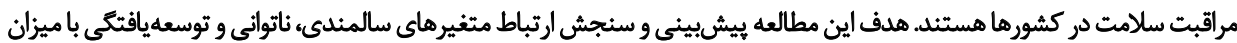

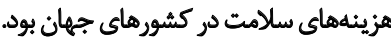

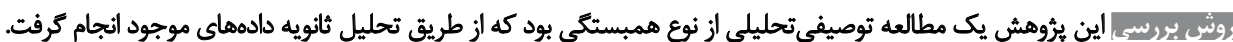

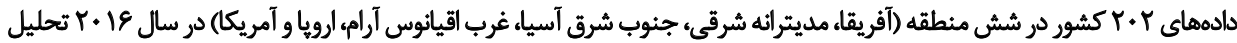

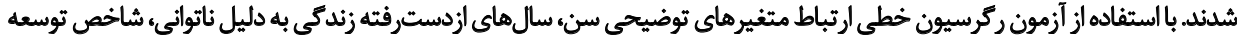

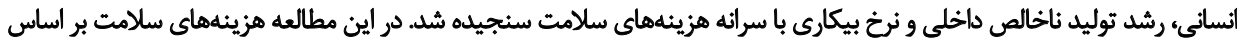

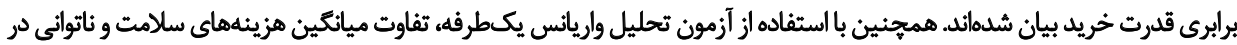

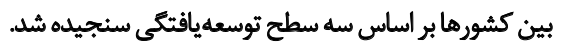

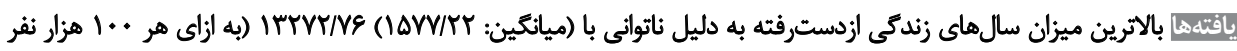

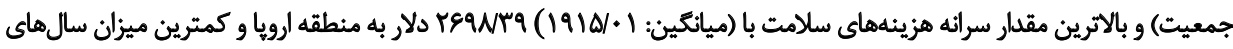

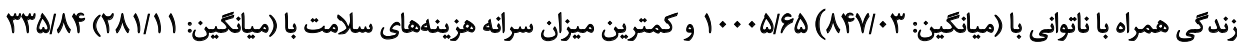

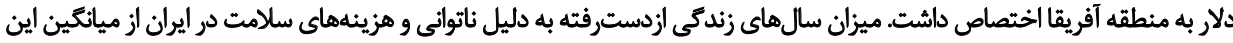

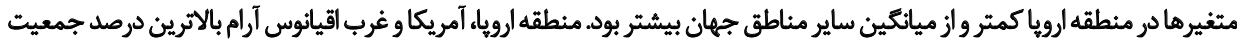

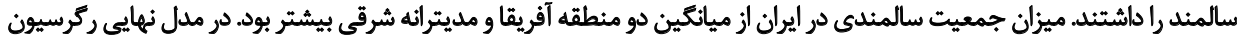

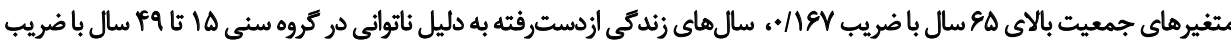

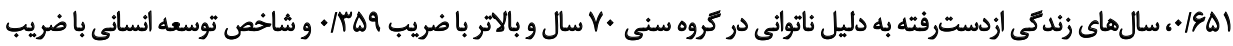

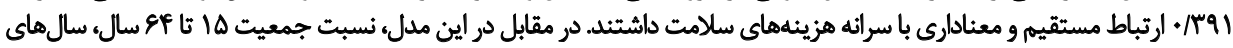

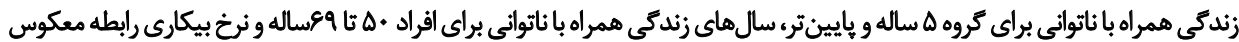

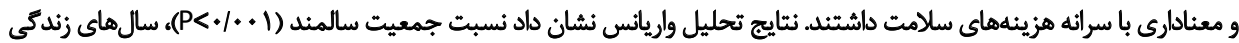

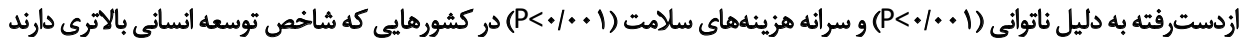

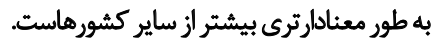

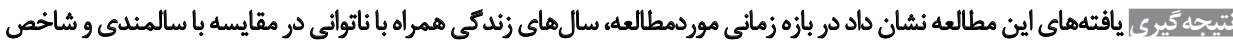

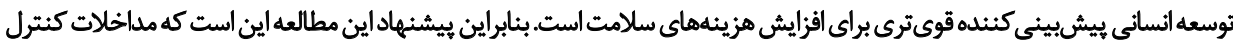

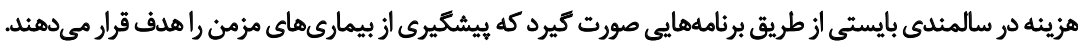

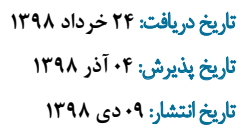

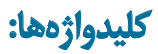

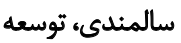

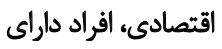
ناتوانى، بار جهانى أفراني

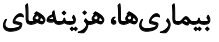

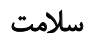




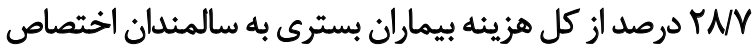
مelod

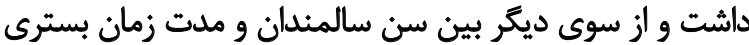

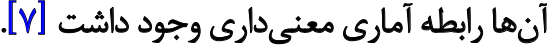

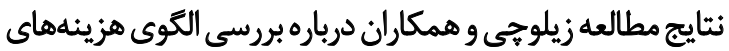

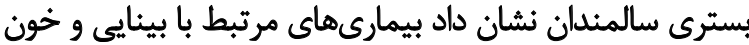

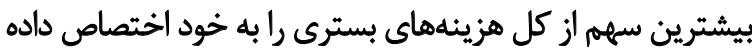

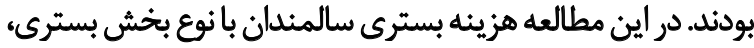

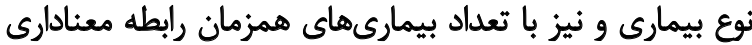

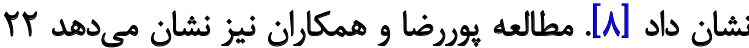

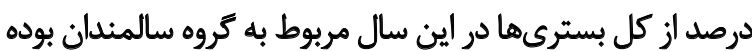

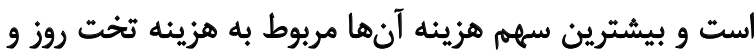

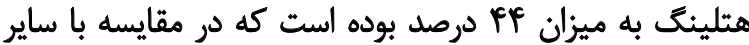

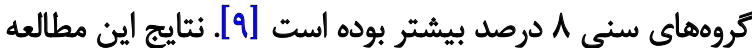

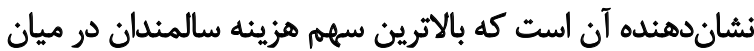

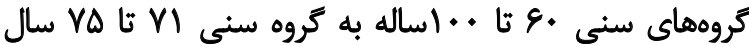

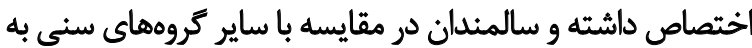
طول مدت اقامت بيشترى در بيمارستان نياز دارند.

يكى از عوامل مهم در بيشبينى هزينهافهاى سلامت توجه به به بهات

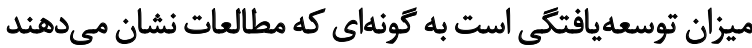

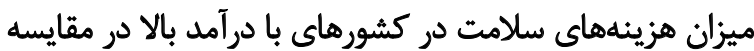

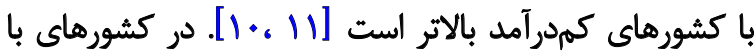

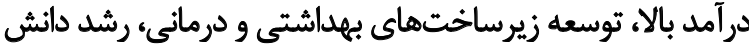

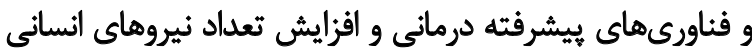

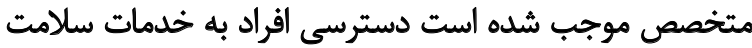

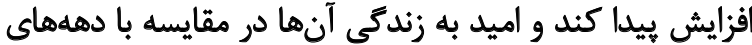

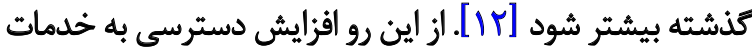

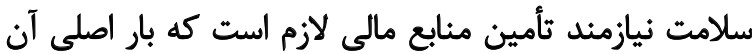

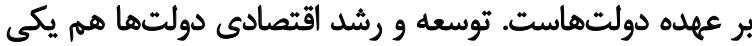

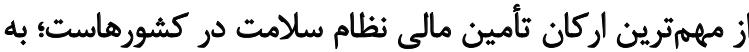

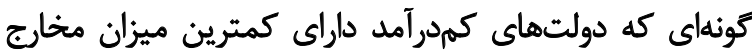

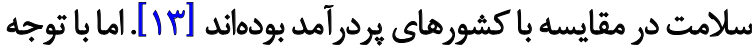

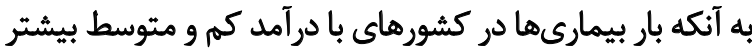

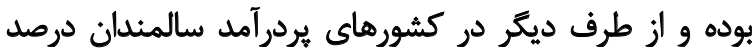

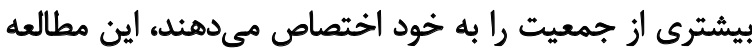

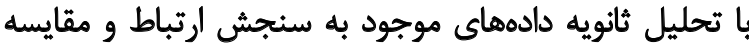

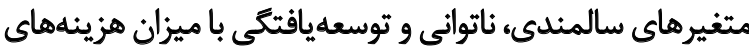
سلامت در كشورهاى جهان يرداخته است

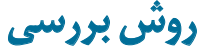

اين بثروهش يك مطالعه توصيفى تحليلى از نوع همبستخى بود

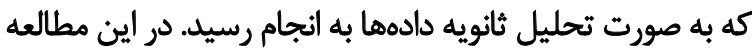

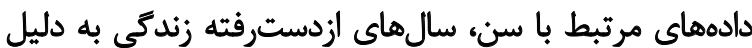

كزارش منتشرشده از سوى سازمان جهاني بهداشت نشان

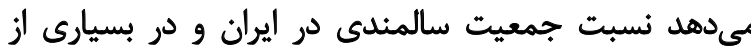

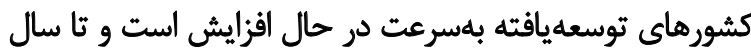

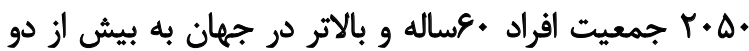

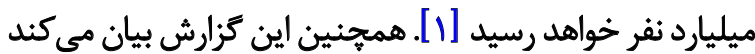

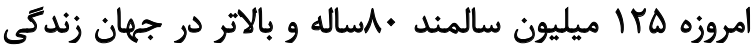

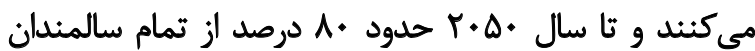

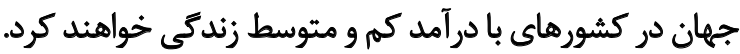
ورود به دوره سالمندى مى تواند باعث افزايش ميزان استفاده

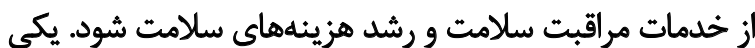

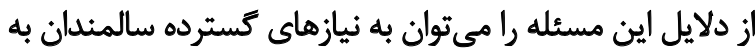

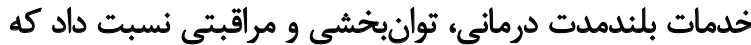

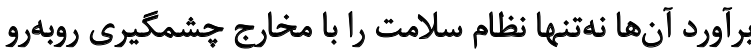

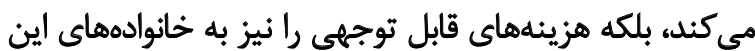

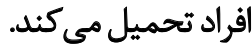

يافتههاى مطالعات مختلف در سطح بينالملل بر تركيبى از

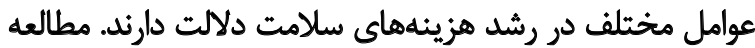

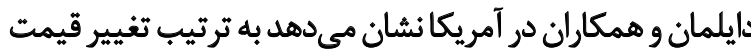

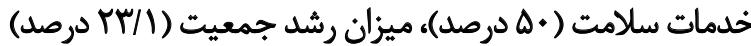

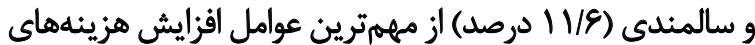

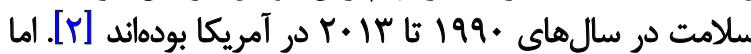

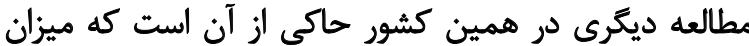

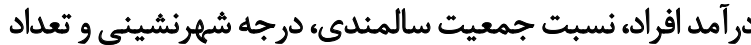

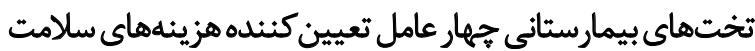

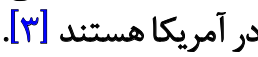

مطالعه كاب فارت و همكاران در آلمان نيز نشان ميدهد

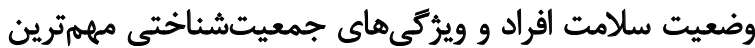

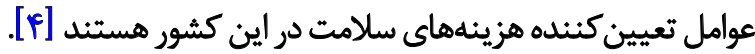

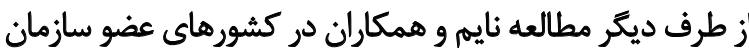

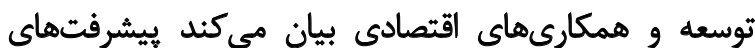

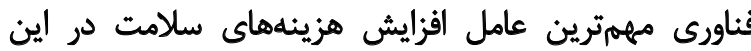

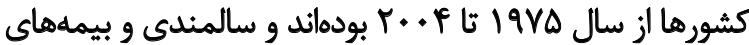

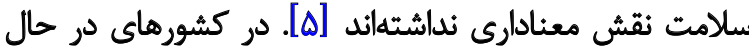

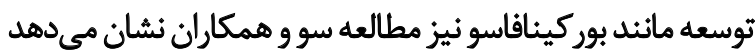

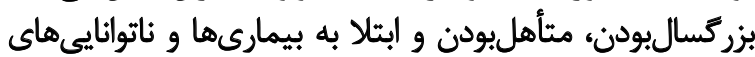

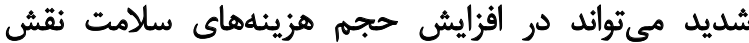
برجستهاى داشته باشند [عاند]

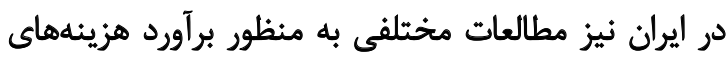

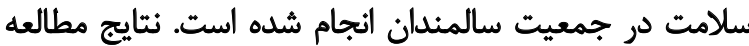

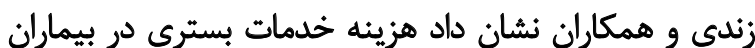

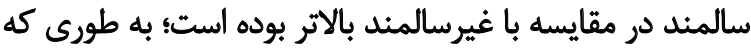




\section{$Y L D=\mid \times D W \times L$}

ا: تعداد موارد بروز يك ناتوائى در يك دوره زمانى؛ DW:

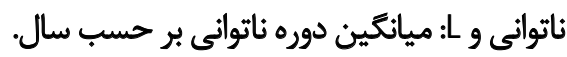

براى محاسبه شاخص توسعه انساني از متغيرهايي استفاده مىشود كه بيانگر وضعيت بهداشت و و سلامت، آموزش و و

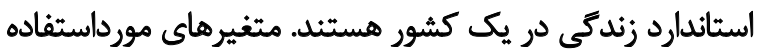

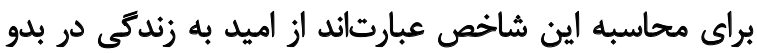

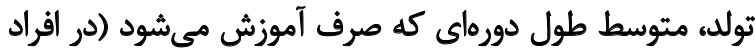

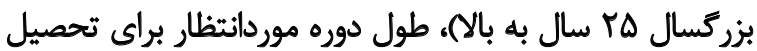

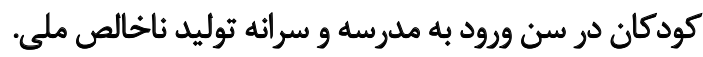

1.

در اين مطالعه دادههاى مربوط به ب +r كشور در سطح جهان

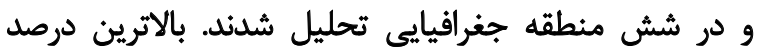

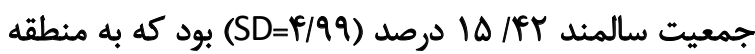

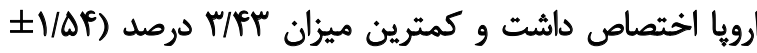

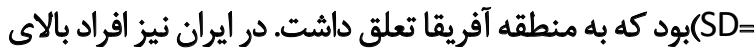

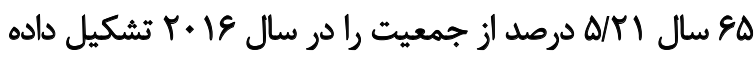

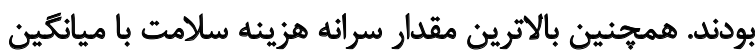

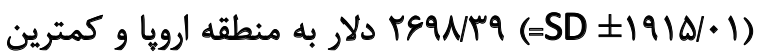

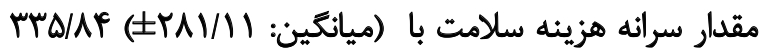

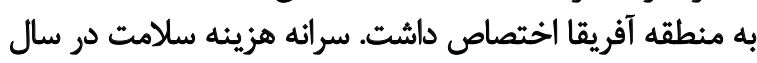

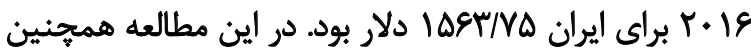

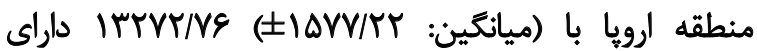

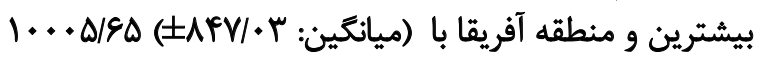

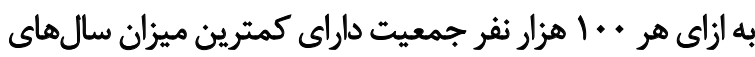
ازدسترفته زندكي به دليل ناتواني بودند.

تصوير شماره | شيوع سالهاي ازدسترفته زندكى به به دليل

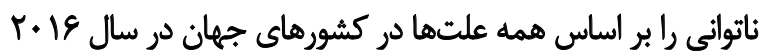

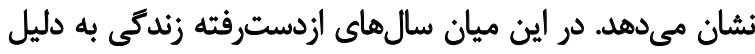

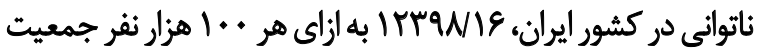

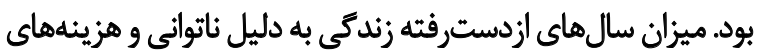

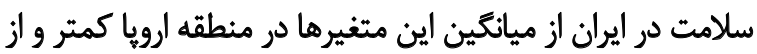

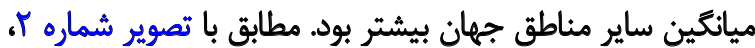

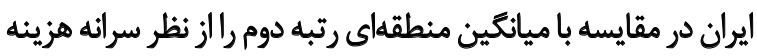

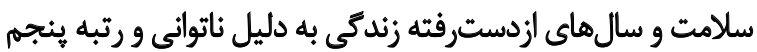

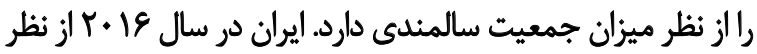

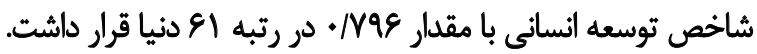
بالاترين مقدار شاخص توسعه انسانى در منطقه ارويا با ميانئين مقين

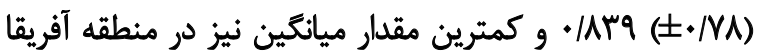

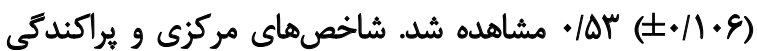

ناتواني'، شاخص توسعه انساني '، نرخ بيكارى (به عنوان درصدى

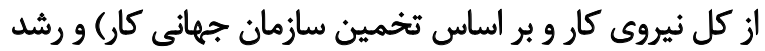

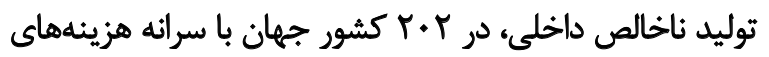

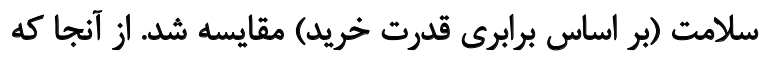

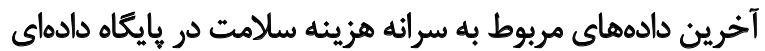

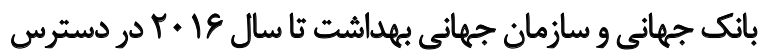

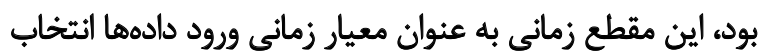

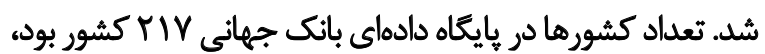
ولي با توجه به نبود دادههاي موردهدف مطالعه براي ها هادئ كشور،

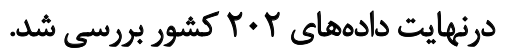

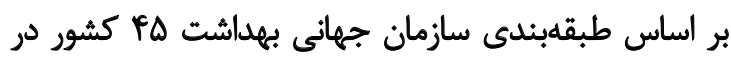

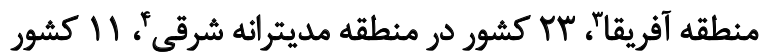

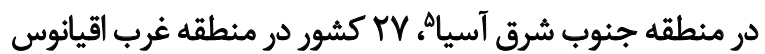

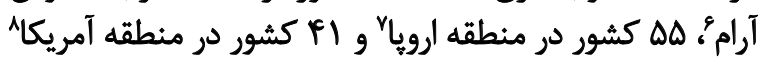

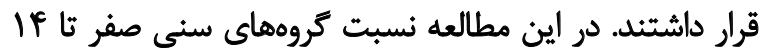

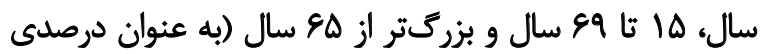

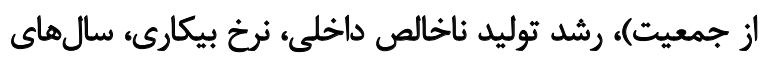

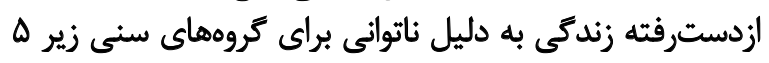

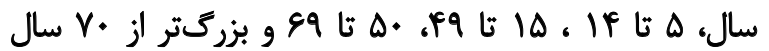
به عنوان متغيرهاى توضيحى و سرانه مخارج سلامت (بر اساس

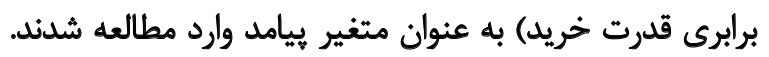

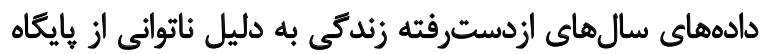

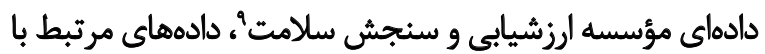

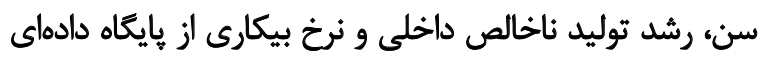

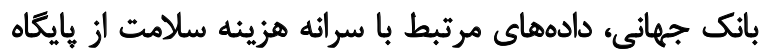

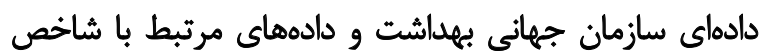

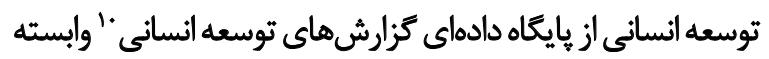
به سازمان ملل استخراج شُ أند.

براى محاسبه سالهاي ازدسترفته زندكي به دليل ناتوانى براي يك علت خاص ودر يك دوره زماني معينه تعداد موارد بروز

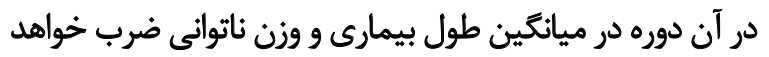

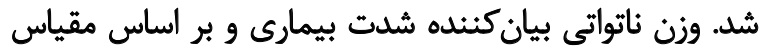

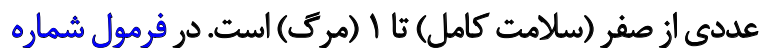

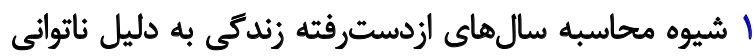

آمده است [if [if]

1. Years Lost due to Disability (YLD)

2. Health Development Index (HDI)

3. African Region (AFRO)

4. Eastern Mediterranean Region (EMRO)

5. South-East Asia Region (SEARO)

6. Western Pacific Region (WPRO)

7. European Region (EURO)

8. Region for the Americas (PAHO)

9. Institute for Health Metrics and Evaluation (IHME)

10. Human development reports 

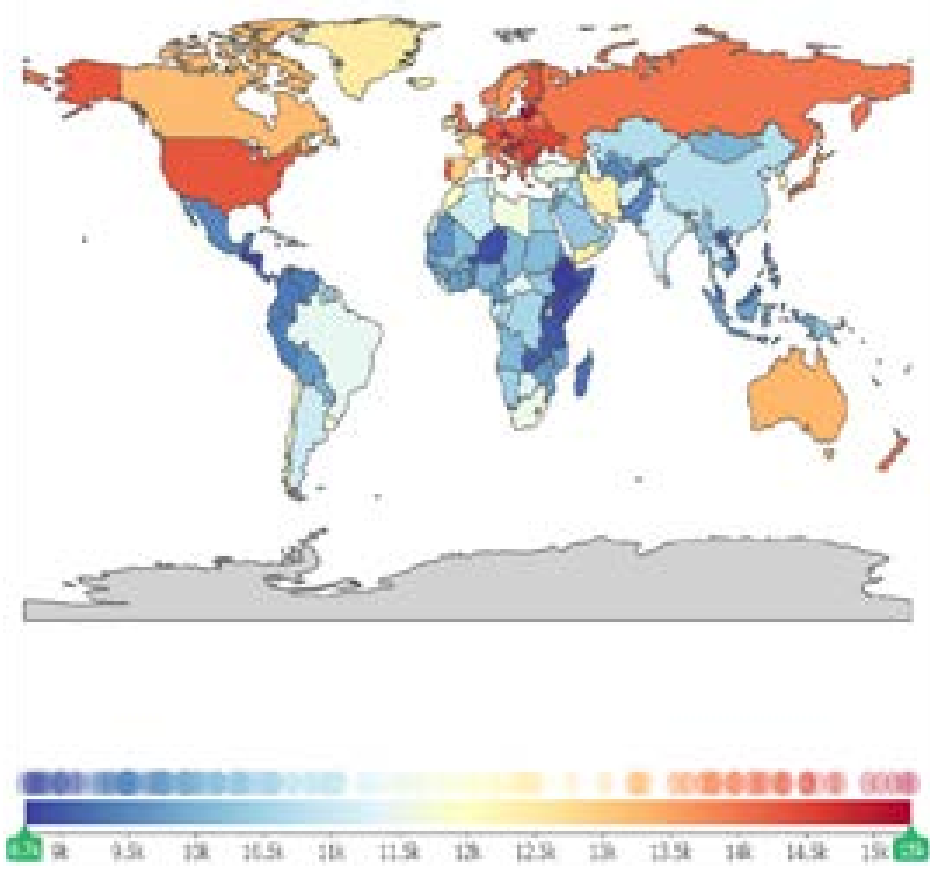

توانبخننى تصوير (. سالهاى زئدكى ازدسترفته به دليل ناتوانى براى همه كروهماى سنى و همه علل ناتوانى در سال 19. T

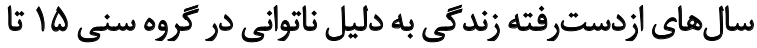

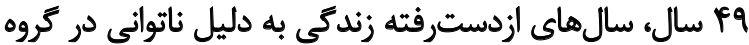

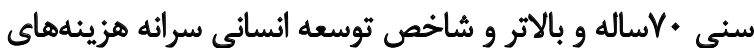

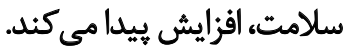

در مقابل، تحليل ركرسيون نشان داد سالهاى ازدسترفته

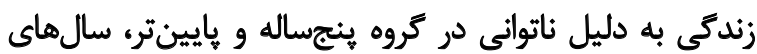

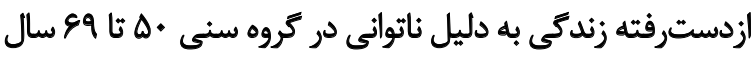

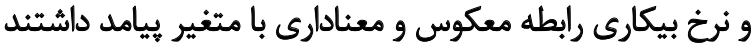

متغير هاى توضيحى مطالعه در جدول شماره إنشان داده شده است. جدول شماره Y ارتباط متغيرهاى توضيحى را با متغير بيامد

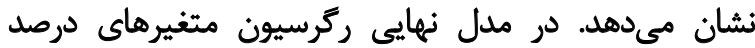

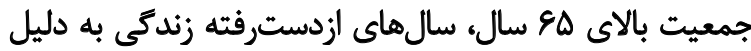

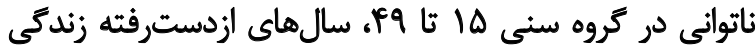

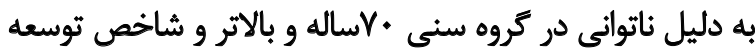

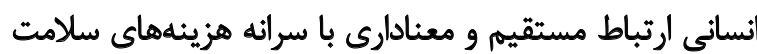

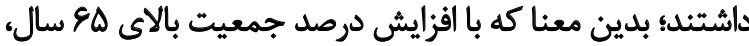

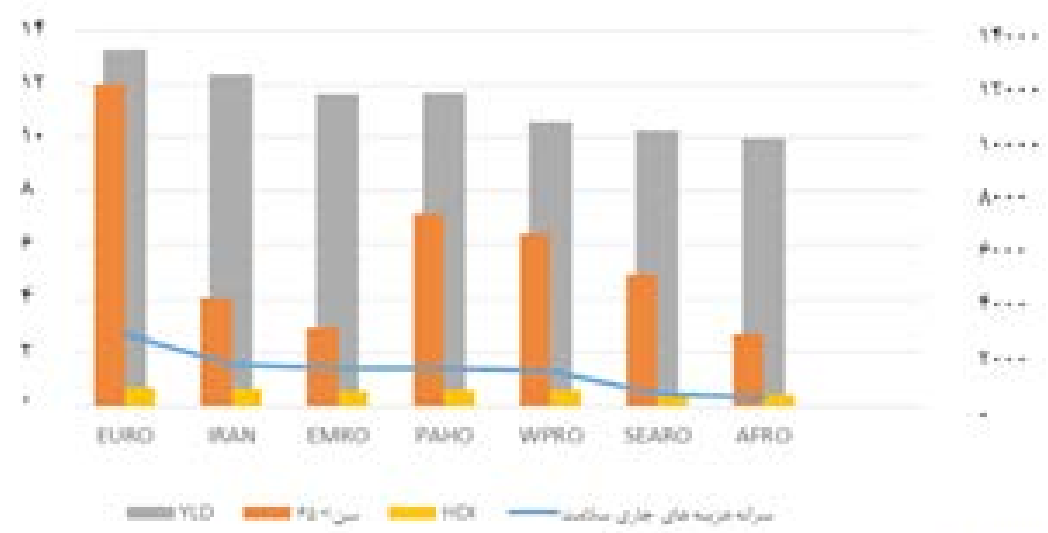

توانبخننى

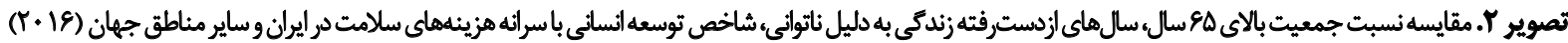


جدول أـ آمارههاي توصيفى متغيرهاى موردمطالعه در مناطق شش قائه موردبررسى

\begin{tabular}{|c|c|c|c|c|c|c|}
\hline شاخص توسعه & 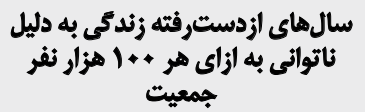 & جمعيت بالاى 70 & بيكارى & سرائه هزيثه & توصيفيى آمارهي & منطقه \\
\hline . $/ \Delta T^{\prime}$ & $\mid \cdots \Delta /{ }^{\prime}$ & $r / 4 \pi$ & $N \cdot 1$ & YAM/II & ميانكين & \\
\hline Fo & Fo & $\mu$ & pif & $F \Delta$ & تعلاد & AFRO \\
\hline .11 .8 & AFY/.r & V/AF & glar & $M T \Delta / A F$ & انحراف معيار & \\
\hline $.18 A$ & $119 V \cdot / F^{2}$ & $r / \Lambda$ & $9 / 4$ & IFtriefe & ميانكين & \\
\hline rr & $M$ & r & r & 18 & تعلاد & EMRO \\
\hline.$/ 1 F$ & $r q .4 / . q$ & V/Ar & e/N & Iretar & انحراف معيار & \\
\hline . $/ A M$ & ITrN/Ve & $\mid Q / P r$ & VII & requTa & هيانكين & \\
\hline$\Delta r$ & (1) & D) & $\Delta 1$ & $\Delta r$ & تعلاد & EURO \\
\hline $.1 . v$ & $10 W / \pi r$ & $P / 99$ & $\Delta / \Delta T$ & $1910 / \cdot 1$ & انحراف معيار & \\
\hline$\cdot / M^{F}$ & $11 Y+N T F$ & ר/ז & $V / M$ & Irqv/s & ميأكين & \\
\hline ז' & rv & שg & $\pi$ & m & تعلاد & PAHO \\
\hline $.1+1$ & PYAS/MT & $r / 91$ & $F(\Delta)$ & IVAr/Ta & انحراف معيار & \\
\hline .198 & 1. TAF/AT & $8 / T^{\circ}$ & ז/M & rTI/ & ميانكين & \\
\hline 1. & 11 & 11 & 11 & 1. & تعلاد & SEARO \\
\hline $.1 \cdot v$ & EAd/AY & $T / \Delta)$ & $1 / \pi T$ & PAT/N & اثحراف معيار & \\
\hline$\cdot M$ & $1 . \Delta A 1 / \Delta A$ & NII & $r / q$ & $\| r \cdot V / F \Delta$ & ميانكين & \\
\hline r & $r$ & r & $M$ & $\pi$ & تعلاد & WPRO \\
\hline . & inne/ei & $\Delta / N E$ & $T / T V$ & 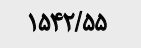 & انحراف معيار & \\
\hline$\cdot N$ & $\| 1 F q . / 4 \mid$ & NF & $V / M$ & $\mid m+m / / 8$ & ميالكين & \\
\hline Wf & 195 & $M$ & MT & in & تعلاد & Total \\
\hline .110 & rqDF/Ir & $81 . V$ & $\Delta / M^{\circ}$ & IVNOY & انحراف معيار & \\
\hline
\end{tabular}

جدول r. مدل ركرسيون عوامل مؤثر بر سرانه هزينههاي سلامت

\begin{tabular}{|c|c|c|c|c|}
\hline \multirow{2}{*}{ معنى سطحى } & \multirow{2}{*}{ ضرايب استاثدارد } & \multicolumn{2}{|c|}{ ضرايب غيراستاندارد } & \multirow{2}{*}{ متغير } \\
\hline & & خطاى استاندارد & B & \\
\hline $.1 \% 1$ & $-a V^{e}$ & IV/ag & $-\Lambda * 1 * \Lambda$ & جمعيث ها تا به سال \\
\hline.$\% 18$ &.$/ 19 V$ & WTIA & Fe/lat & جمعيت بالاى هاء سال \\
\hline$<+/ \cdot+1$ & $-+1 \Delta \alpha$ & .1 .94 & $-* / M M$ & سال هاى ازدستر فته زندكى به دليل ناتواتى در كروه سنى بنجساله و وايينتر \\
\hline 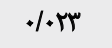 &.$|80|$ & .1 .18 &.$/ 4 E$ & سال هاى ازدسيترفته زتدكى به دليل نائوانى در كروه سنى ها تا هج سال \\
\hline $.1 .+1$ &.$- / 9 T \wedge$ & - NFA & $-\cdot$ Nat & 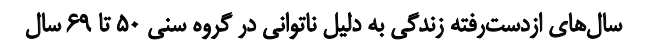 \\
\hline $.1 .+1$ &.$/ T \Delta Q$ & $.1+4$ &.$- / 118$ & 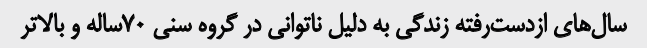 \\
\hline$<+1 . .1$ &.$/ 491$ & ITIT/QTA & MrAT/RT. & شياخص تونسعه أنسيانى \\
\hline$<. . .1$ &.$- / 11 \%$ & $1 f \% \cdot v 9$ & $-\Delta \cdot / r \wedge q$ & ثنخ ييكارى \\
\hline
\end{tabular}


جدول "ب. تفاوت ميانكين متغيرهاى درصد جمعيت سالمند، سال هاى ازدسترفته زندكى به دليل ناتوانى و سرانه هزينه سلامت بر اساس شاخص توسعه أسانى

\begin{tabular}{|c|c|c|c|c|}
\hline \multirow{2}{*}{ سطح معنى دارى } & \multicolumn{3}{|c|}{ مياتكين ثانحراف معيار } & \multirow{2}{*}{ توسعه } \\
\hline & 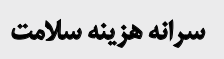 & سالهاى ازدسترفته زندكى (به ازاى + + هزار نفر جمعيت) & درصد جمعيث سالمند & \\
\hline$<+1 .+1$ & $\mid f q / A) \pm \| W V E$ & $99 \Delta \Delta / P V \pm A \cdot \leftarrow / A F$ & $r / M T \pm . / M$ & $(\cdot / r-.18)$ \\
\hline$<.1 . .1$ & VEV/TVEFTH/AF & $\|F+/\| \pm \pm F \| r=/ Q$ & $V / \cdot q \pm r / T r$ & $(\cdot / 8)-\cdot / A)$ \\
\hline$<+1+.1$ & 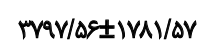 & $I M T N \cdot F \pm I T a Y / F q$ & $|Q / 9 \Delta \pm \Delta / F|$ & $(\cdot|\lambda|-1)$ \\
\hline
\end{tabular}

توانبخننى

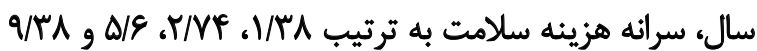

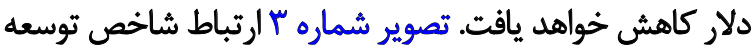

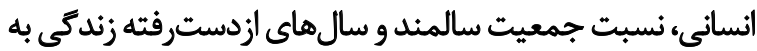

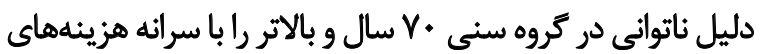

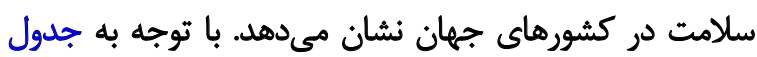

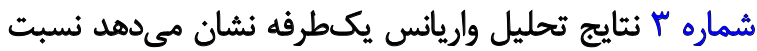

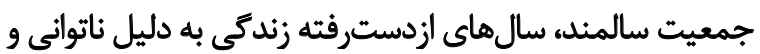

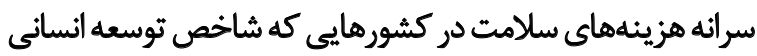
بالاترى دارند به طور معنادارترى بيشتر از ساير كشورهاست سلاست
كه نشان مي دهد با كاهش سال هاي زندكى ازدسترفته به دليل

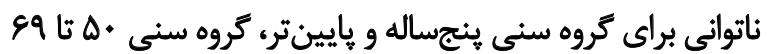

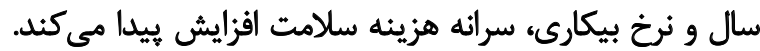

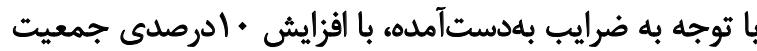

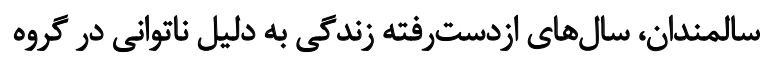

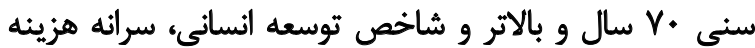

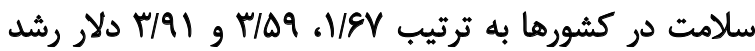

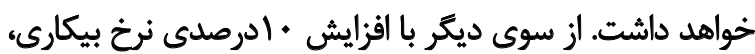

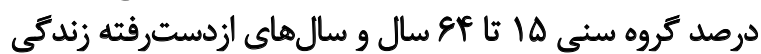

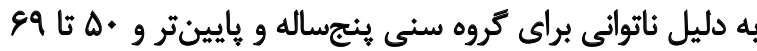
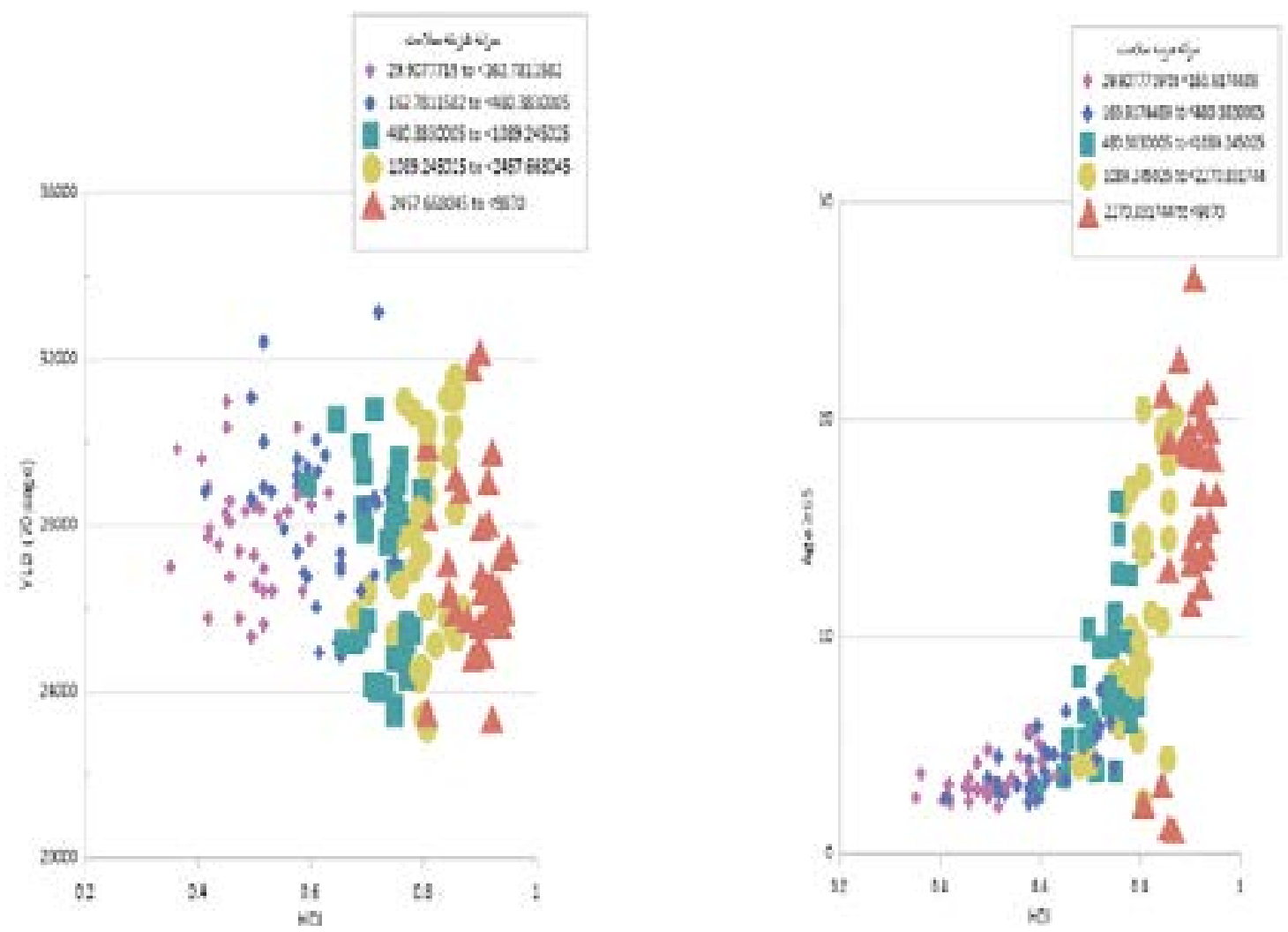

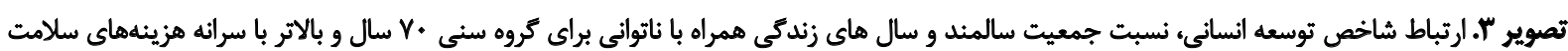
توانبخننى

در كشورهاي جهان در سال 
سلامت و همجنين در خانوادهها هزينه وخدمات بيشترى صرف

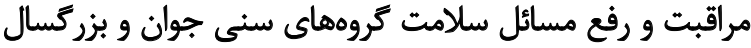

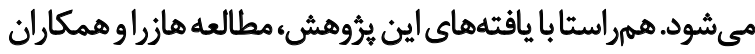

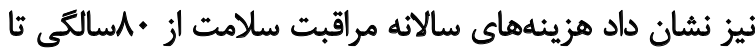

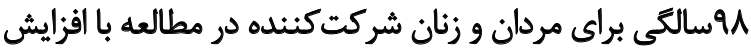

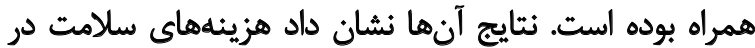

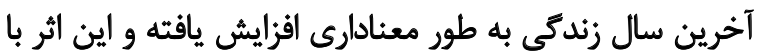

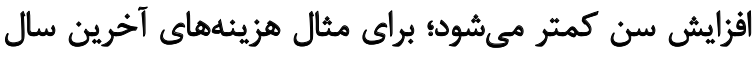

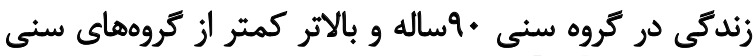

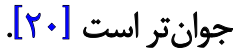

در اين مطالعه همجنين يك ارتباط منفى و معنادار بين سرانه

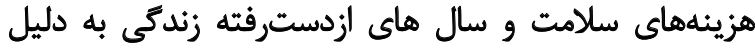

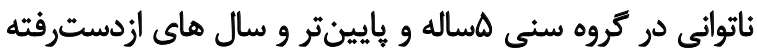

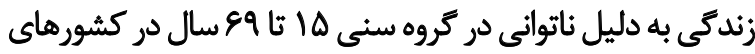

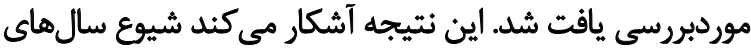

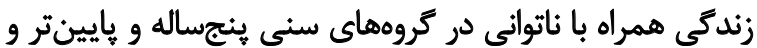

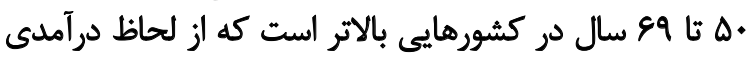

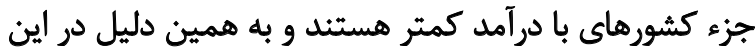

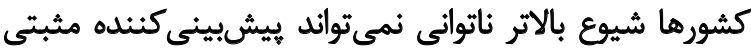

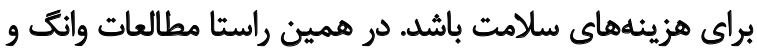

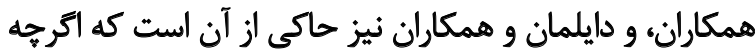

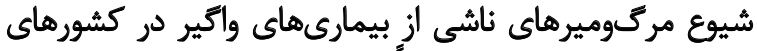

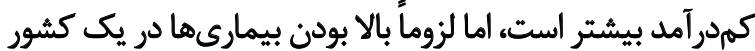

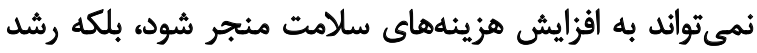

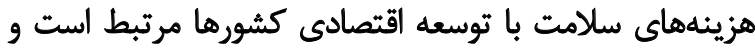

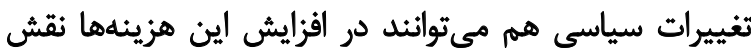

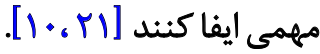

نتايج اين مطالعه نشان مىدهد منطقه آفريقا داراي بالاترين

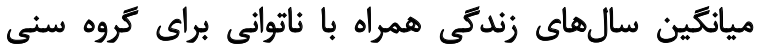

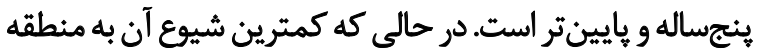

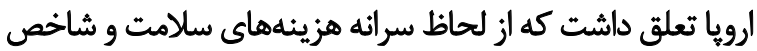

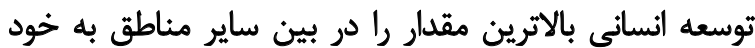

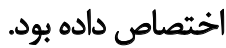

نتايج مطالعه حاضر نشان داد شاخص توسعه انسانى نيز يك

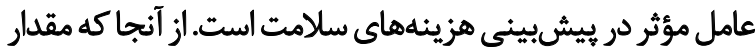

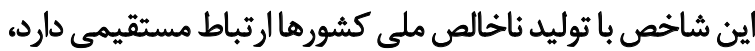

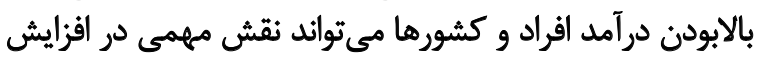

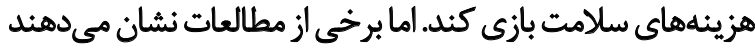

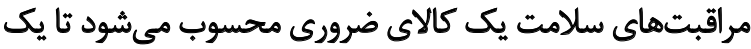

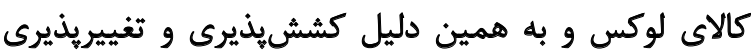

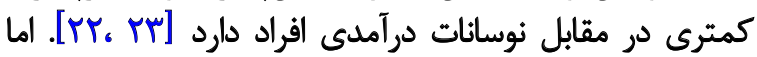
مطالعات تحليل هزينه در سطح كشورها

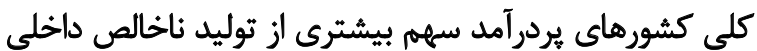

بحث

هدف اين مطالعه تعيين ارتباط شاخصهاي توسعهيافتكى،

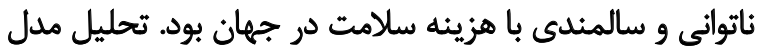

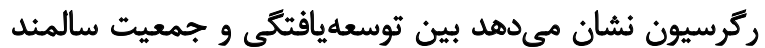

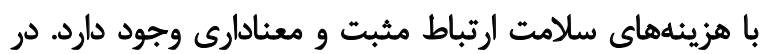

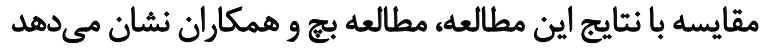

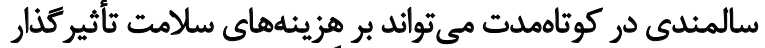

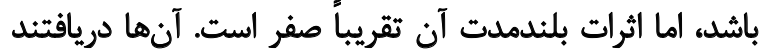

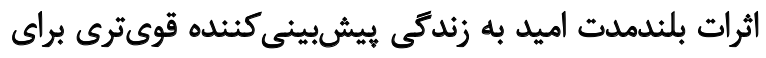

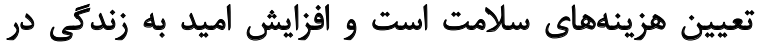

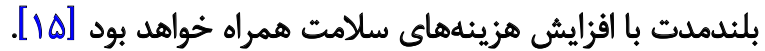

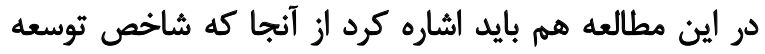

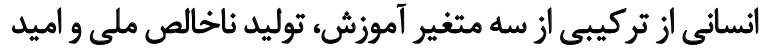

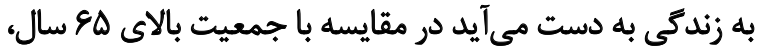

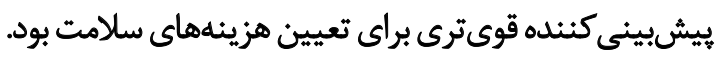
يافتههاى مطالعه حاضر بيانكر آن است كه در مقايسه با متغير

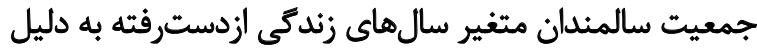

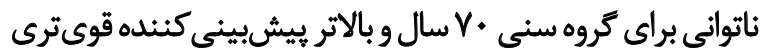

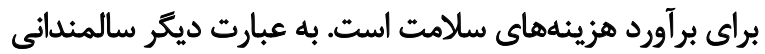

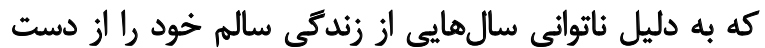

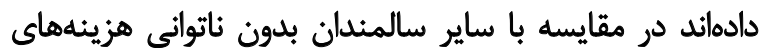

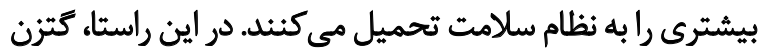

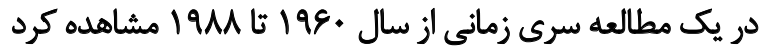

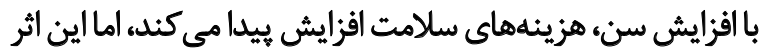

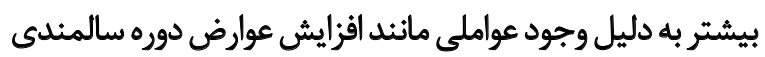

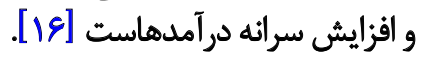

مطالعه هريس و شارما نيز نشان ميدهد هزينهائهاى سلامت

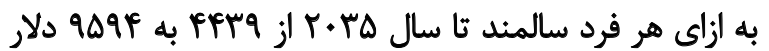
خواهد رسيد و ميانكين رشد سالانه كل هزينه

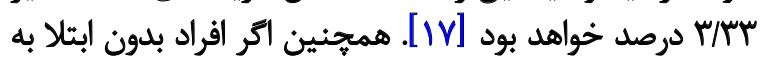

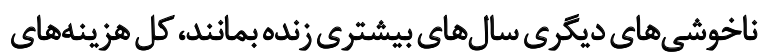

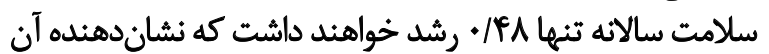

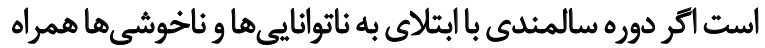

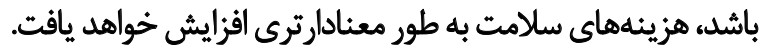

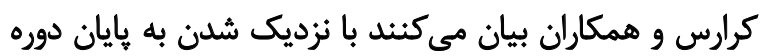

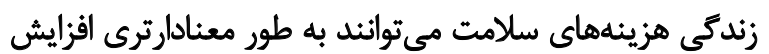

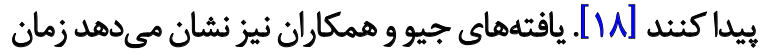

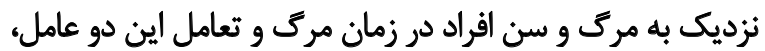

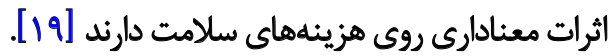

نتايج مطالعه حاضر نشان داد بار بيمارى در تروه سنى جوان بران

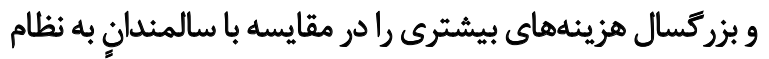

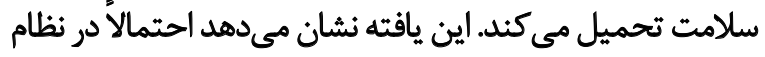




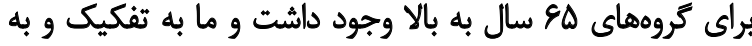

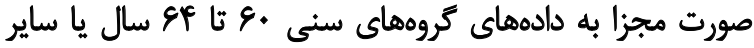

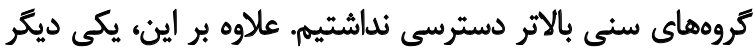

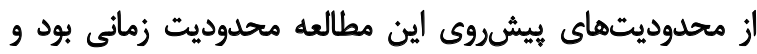

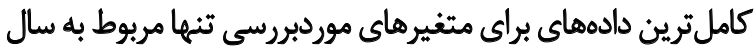

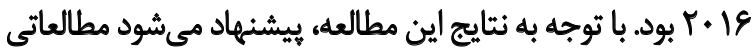

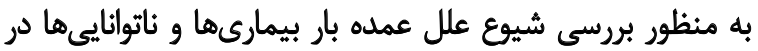

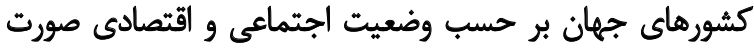

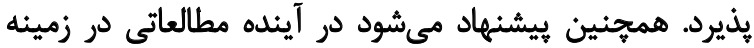

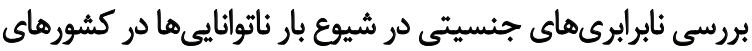
مختلف جهان طراحى و اجرا شود.

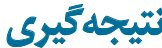

به طور كلى نثايج اين مطالعه نشان مىدهد در در بازه زمانى

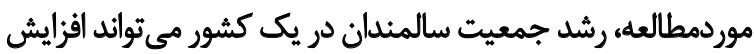

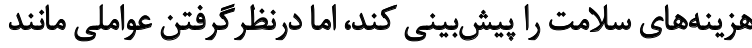

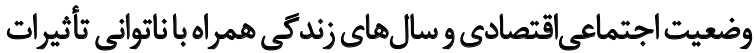
برجستهترى بر افزايش هزينهاعهاي سلامت خواهن

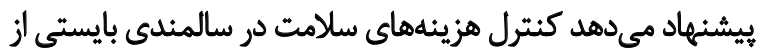

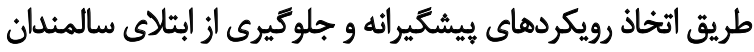

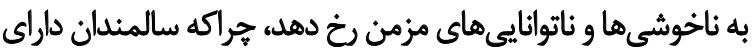

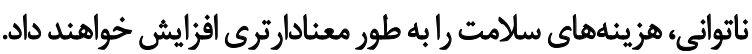

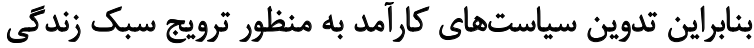

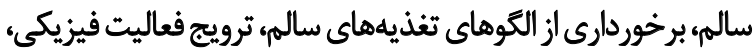

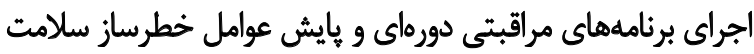

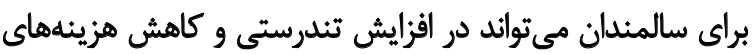

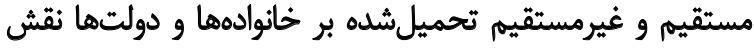

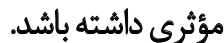

\section{ملاحظاث اخلاقى}

\section{ي ييروى أز اصول اخلاق بثوهش}

اين مقاله حاصل از طرح يُروهشى با كد \& و 9 است. كليه اصول

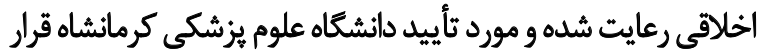

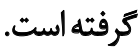

$$
\text { ماهي مالى }
$$

دانشكاه علوم يُزشكى كرمانشاه از اين مطالعه حمايت كرده است.

$$
\text { مشاركت نويسندكان }
$$

مفهومسازى: شاهين سلطانى و بهزاد كرمى متين؛ روشئ كانساسى:

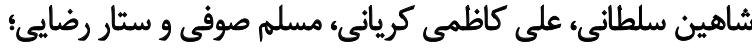

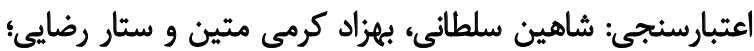

خود را به هزينههاي سلامت اختصاص مي دهند [11 ـ11].

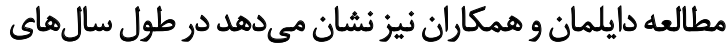

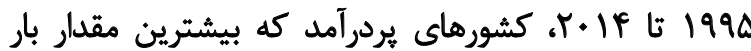

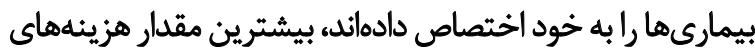

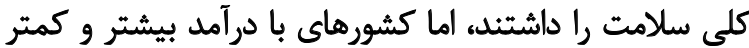

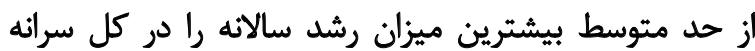

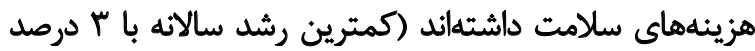

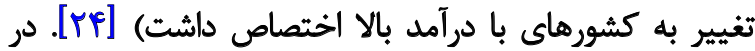

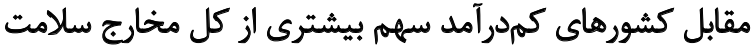

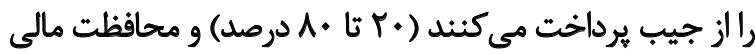

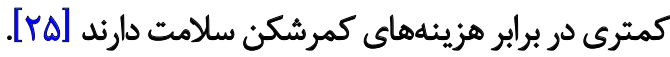
مطالعه كومارا و سامارتانك در سريلانكا بيانكر آن بود كه

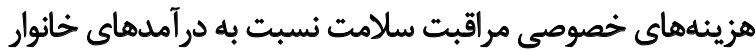

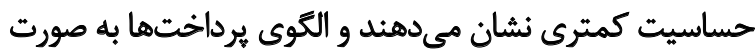

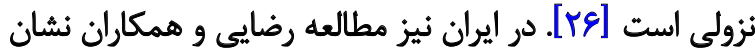

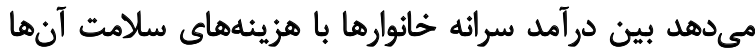

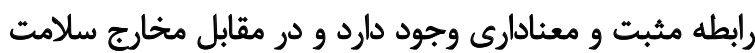
كششيذيرى كمترى نسبت به تغييرات درآمدى خداني خانوارها نشان

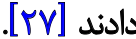

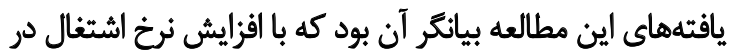

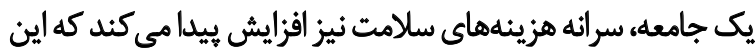

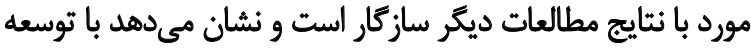

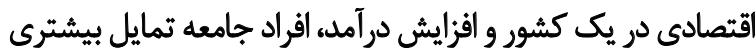
براى استفاده از خدمات سلامت و ايجاد هزينهائهاى بيشتر خواهي

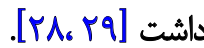

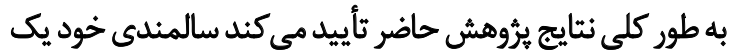

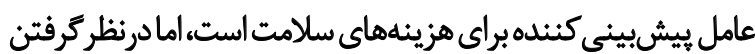

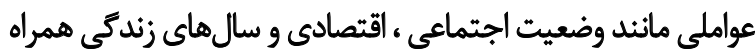

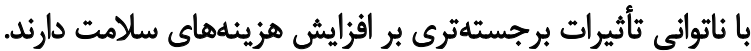

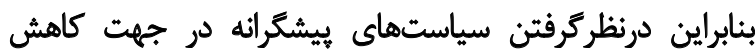

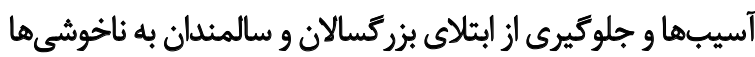

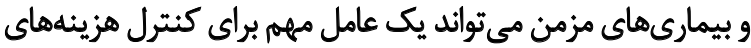

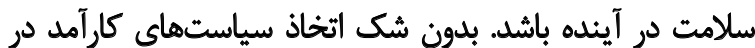

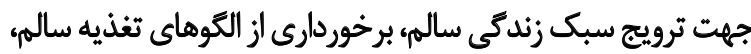

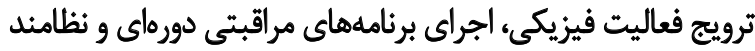

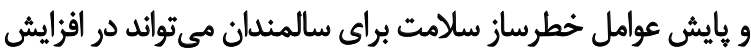

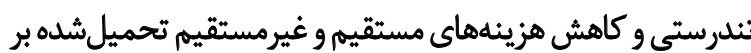

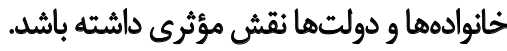

از آنجا كه اين مطالعه با استفاده از دادههاي موجود در بائكاههاي

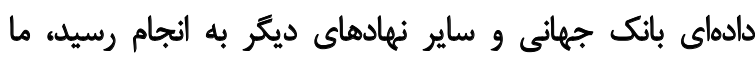

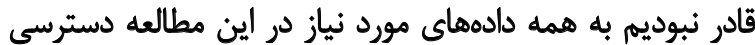

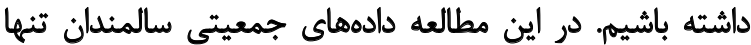


تحليل: شاهين سلطانى، على كاظمى و مسلم صوفى؛ تحقيق و

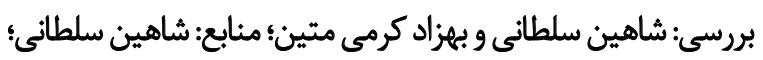

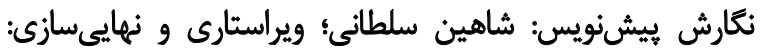

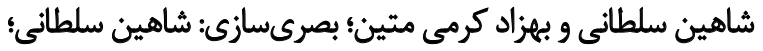
نظارت: بهزاد كرمى متين؛ مديريث يروزه: بهزاد كرمئ مئي متين.

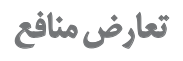

نويسندكان اين مطالعه اعلام مي دارند كه در انجام اين مطالعه و انتشار نتايج آن تضاد منافعى وجود نداشته است.

$$
\text { تشيكر و قدرواني }
$$

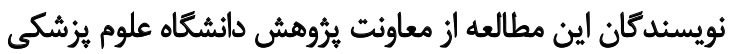

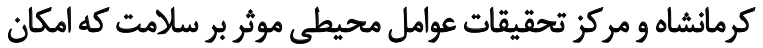
اجراى اين يُروهش را فراهم نمودند كمال تشكر و قدردانى را دارند. 


\section{References}

[1] World Health Organization. World report on ageing and health. Geneva: World Health Organization; 2015.

[2] Dieleman, JL, Squires E, Bui AL, Campbell M, Chapin A, Hamavid $\mathrm{H}$, et al. Factors associated with increases in US health care spending, 1996-2013. Journal of the American Medical Association. 2017; 318(17):1668-78. [DOI:10.1001/jama.2017.15927] [PMID] [PMCID]

[3] Wang Z. The determinants of health expenditures: Evidence from US state-level data. Applied Economics. 2009; 41(4):429-35. [DOI:10.1080/00036840701704527]

[4] Göpffarth D, Kopetsch T, Schmitz H. Determinants of regional variation in health expenditures in Germany. Health Economics. 2016; 25(7):801-15. [DOI:10.1002/hec.3183] [PMID]

[5] Nghiem SH, Connelly LB. Convergence and determinants of health expenditures in OECD countries. Health Economics Review. 2017; 7(1):29. [DOI:10.1186/s13561-017-0164-4] [PMID] [PMCID]

[6] Su TT, Pokhrel S, Gbangou A, Flessa S. Determinants of household health expenditure on western institutional health care. The European Journal of Health Economics. 2006; 7(3):195-203. [DOI:10.1007/s10198-006-0354-1] [PMID]

[7] Zandi Sh, Pourreza A, Salavati S. [The study of consumption pattern and hospitalization costs of elderly covered by Iran Health Insurance Organization (Persian)]. Health-Based Research. 2016; 2(1):15-27.

[8] Ziloochi MH, Pourreza A, Akbari F, Rahimi-Foroshani A. [Evaluating the hospitalization costs for elderly patients in teaching hospitals of Kashan University of Medical Sciences during 2009-10 (Persian)]. Feyz. 2012; 16(1):86-94.

[9] Pourreza A, Mir Mohammadkhani M, Pooragha B. [The illness patterns and their costs among hospitalized elderly covered by medical service insurance organization, in Damghan's Hospitals, in year of 2005-2006 (Persian)]. Salmand. 2007; 2(2):252-62.

[10] Dieleman JL, Campbell M, Chapin A, Eldrenkamp E, Fan VY, Haakenstad A, et al. Future and potential spending on health 201540: Development assistance for health, and government, prepaid private, and out-of-pocket health spending in 184 countries. The Lancet. 2017; 389(10083):2005-30. [DOI:10.1016/S01406736(17)30873-5]

[11] Jakovljevic M, Getzen TE. Growth of global health spending share in low and middle income countries. Frontiers in Pharmacology. 2016; 7(21):1-4. [DOI:10.3389/fphar.2016.00021] [PMID] [PMCID]

[12] Rasel M, Ardalan A. [The future of ageing and its health care costs: A warning for health system (Persian)]. Salmand. 2007; 2(2):300-5.

[13] Khosravi B, Soltani S, Javan-Noughabi J, Faramarzi A. Health care expenditure in the Islamic Republic of Iran versus other high spending countries. Medical Journal of the Islamic Republic of Iran. 2017; 31:71. [DOI:10.14196/mjiri.31.71] [PMID] [PMCID]

[14] Baylin A, Rougemont A, Torres A, Ammon C, Schopper D, Pereira J, et al. Estimating the burden of disease in one Swiss canton: What do Disability Adjusted Life Years (DALY) tell us?
International Journal of Epidemiology. 2000; 29(5):871-7. [DOI:10.1093/ije/29.5.871] [PMID]

[15] Bech M, Christiansen T, Khoman E, Lauridsen J, Weale M. Ageing and health care expenditure in EU-15. The European Journal of Health Economics. 2011; 12(5):469-78. [DOI:10.1007/ s10198-010-0260-4] [PMID]

[16] Getzen TE. Population aging and the growth of health expenditures. Journal of Gerontology. 1992; 47(3):S98-104. [DOI:10.1093/geronj/47.3.S98]

[17] Harris A, Sharma A. Estimating the future health and aged care expenditure in Australia with changes in morbidity. PloS One. 2018; 13(8):e0201697. [DOI:10.1371/journal. pone.0201697] [PMID] [PMCID]

[18] Carreras M, Ibern P, Inoriza JM. Ageing and healthcare expenditures: Exploring the role of individual health status. 2018; 27(5):865-76. [DOI:10.1002/hec.3635] [PMID]

[19] Geue C, Briggs A, Lewsey J, Lorgelly P. Population ageing and healthcare expenditure projections: New evidence from a time to death approach. The European Journal of Health Economics. 2014; 15(8):885-96. [DOI:10.1007/s10198-013-05437] [PMID]

[20] Hazra NC, Rudisill C, Gulliford MC. Determinants of health care costs in the senior elderly: Age, comorbidity, impairment, or proximity to death? The European Journal of Health Economics. 2018; 19(6):831-42. [DOI:10.1007/s10198-017-09262] [PMID] [PMCID]

[21] Wang $\mathrm{H}$, Abajobir AA, Abate $\mathrm{KH}$, Abbafati $\mathrm{C}$, Abbas KM, AbdAllah $F$, et al. Global, regional, and national under-5 mortality, adult mortality, age-specific mortality, and life expectancy, 1970-2016: A systematic analysis for the global burden of disease study 2016. The Lancet. 2017; 390(10100):1084-150. [DOI:10.1016/S0140-6736(17)31833-0]

[22] Moscone F, Tosetti E. Health expenditure and income in the United States. Health Economics. 2010; 19(12):1385-403. [DOI:10.1002/hec.1552] [PMID]

[23] Baltagi BH, Moscone F. Health care expenditure and income in the OECD reconsidered: Evidence from panel data. Economic Modelling. 2010; 27(4):804-11. [DOI:10.1016/j.econmod.2009.12.001

[24] Dieleman JL, Sadat N, Chang AY, Fullman N, Abbafati C, Acharya $P$, et al. Trends in future health financing and coverage: Future health spending and universal health coverage in 188 countries, 2016-40. The Lancet. 2018; 391(10132):1783-98. [DOI:10.1016/S0140-6736(18)30697-4]

[25] Musgrove P, Zeramdini R, Carrin G. Basic patterns in national health expenditure. Bulletin of the World Health Organization. 2002; 80(2):134-42. [PMID] [PMCID]

[26] Kumara AS, Samaratunge R. Patterns and determinants of outof-pocket health care expenditure in Sri Lanka: evidence from household surveys. Health Policy and Planning. 2016; 31(8):97083. [DOI:10.1093/heapol/czw021] [PMID]

[27] Rezaei S, Dindar A, Rezapour A. [Health care expenditures and their determinants: Iran Provinces (2006-2011) (Persian)] Journal of Health Administration. 2016; 19(63):81-90. 
[28] Gudlavalleti MV, John N, Allagh K, Sagar J, Kamalakannan S, Ramachandra SS, et al. Access to health care and employment status of people with disabilities in South India, the SIDE (South India Disability Evidence) study. BMC Public Health. 2014; 14:1125. [DOI:10.1186/1471-2458-14-1125] [PMID] [PMCID]

[29] Maart S, Jelsma J. Disability and access to health care- a community based descriptive study. Disability and Rehabilitation. 2014; 36(18):1489-93. [DOI:10.3109/09638288.2013.807883 ] [PMID] 